\title{
Determinantes dos Investimentos Diretos Externos Chineses: Aspectos Econômicos e Geopolíticos*
}

Leandro Teixeira dos Santos** e Marcelo Milan***

\section{Introdução}

A China atrai a atenção pelo rápido crescimento econômico e pelo aumento de seu peso nos grandes debates internacionais, incluindo mudanças climáticas, superação da crise financeira mundial, manutenção da paz e a reorganização das relações internacionais de poder. Neste sentido, uma das discussões que tem despertado o interesse

\footnotetext{
* Artigo enviado em 13 de agosto de 2013 e aprovado para publicação em 6 de junho de 2014. Os autores agradecem os comentários e sugestões de um parecerista anônimo, isentando-o de eventuais erros e omissões.

** Doutorando em Estudos Estratégicos Internacionais pela Universidade Federal do Rio Grande do Sul (UFRGS) e membro do Núcleo de Estudos do BRICS (NEBRICS). E-mail: teixeirasantospe@gmail.com.

*** Doutor em Economia pela Universidade de Massachusetts Amherst e professor adjunto II do Departamento de Economia e Relações Internacionais e dos Programas de Pós-graduação em Economia e em Estudos Estratégicos Internacionais da Universidade Federal do Rio Grande do Sul (UFRGS) e membro do Núcleo de Estudos dos BRICS (NEBRICS). E-mail: milan.econ@gmail. com.
}

CONTEXTO INTERNACIONAL Rio de Janeiro, vol. 36, nㅜ 2, julho/dezembro 2014, p. 457-486. 
entre os pesquisadores é a participação do país no fluxo de investimentos internacionais, notadamente os Investimentos Diretos Externos (IDEs). Segundo dados da Conferência das Nações Unidas sobre Comércio e Desenvolvimento (UNCTAD, 2012b), o país vem aumentando a sua participação no total mundial, como receptor e como fonte dos IDEs.

O aumento dos fluxos de entrada pode ser explicado pelas políticas governamentais chinesas pós-abertura, no sentido de atrair capitais estrangeiros para aumentar o crescimento e fornecer tecnologias, know-how e outros benefícios produzidos pelos IDEs. As saídas, além da busca de tecnologias e know-how, ${ }^{1}$ são motivadas pela grande disponibilidade de divisas do país, pela necessidade de adquirir ativos essenciais, entre eles os recursos naturais, e pelas políticas de incentivos às Empresas de Propriedade do Estado (EPEs), ${ }^{2}$ como a intitulada "Atuação Global". A hipótese deste artigo é de que parte dessas saídas pode responder também a objetivos geopolíticos de Pequim, aspecto não considerado pelas perspectivas tradicionais que tratam da internacionalização das empresas. O objetivo do trabalho é então apresentar elementos que permitam ilustrar esta possível característica dos IDEs chineses. Adicionalmente, sustenta-se que as perspectivas tradicionais podem ser ampliadas, incorporando um novo determinante dos IDEs chineses: a busca de poder nacional.

Além dessa introdução e das considerações finais, este artigo está divido em três outras seções. Na segunda seção, discutem-se as teorias da internacionalização de empresas a partir da ótica dos IDEs, enfatizando os seus argumentos teóricos e as suas insuficiências. Na seção seguinte, abordam-se os IDEs chineses, destacando sua evolução recente e seus determinantes, e apresentando elementos que permitem sugerir que alguns deles obedecem a interesses geopolíticos. Na penúltima seção, propõe-se a ampliação da Teoria Eclética de Jonh Dunning para que possa, entre os determinantes dos IDEs, incorporar aspectos geopolíticos, como a busca de poder nacional. 
Determinantes dos Investimentos Diretos

Externos Chineses: Aspectos Econômicos...

\section{Teorias da \\ Internacionalização de \\ Empresas}

Esta seção discute algumas das principais teorias da internacionalização de empresas, sem ser exaustiva. Contribuições importantes como as de Cantwell (1989), Caves (1971), Kindleberger (1969), Kogut e Zander (2003) e Pitelis e Sugden (2000), enfatizando elementos como o papel da inovação, da tecnologia e do conhecimento na internacionalização das empresas, não são abordadas por razão de espaço.

Stephen Hymer (1960) desenvolveu a Teoria do Poder de Mercado para rejeitar a tese de que os IDEs se moveriam pela diferença da taxa de juros entre países. O autor defende que essas inversões são determinadas pela extensão das operações internacionais, sendo que estas se "referem à propriedade e ao controle de empresas em um país por firmas em outros países" (HYMER, 1960, p. 3). Dessa forma, explica a extensão das operações internacionais e o movimento de capital associados a estas. Segundo Hymer (2003, p. 3), as duas causas das operações internacionais são: 1) "As firmas controlam empresas em muitos países com a intenção de eliminar a competição entre elas quando vendem nos mesmos mercados ou vendem uma para outra sob condições de competição imperfeita" e 2) "As firmas envolvem-se em operações em um país estrangeiro com a intensão de se apropriar completamente dos retornos seguros de habilidades que elas possuem".

Essas explicações derivam de seu entendimento de que os mercados são imperfeitos, o que resulta em custos adicionais às atividades externas das empresas, os quais podem ser minimizados caso exerçam controle sobre sua produção no exterior. As imperfeições do mercado fazem com que, ao invés de as empresas utilizarem métodos alternativos para expandirem suas atividades além das fronteiras domés- 
ticas, como o licenciamento, a exportação e a venda ou o aluguel de

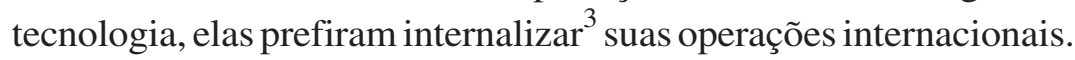
O objetivo é reduzir os custos resultantes dessas imperfeições e manter o controle sobre vantagens que lhes são particulares, tendo em vista que, para Hymer (1960, p. 48): “A empresa é como um dispositivo institucional prático que substitui o mercado. A empresa internaliza ou substitui o mercado." Ela igualmente internaliza a produção para continuar exercendo o controle sobre suas vantagens específicas: capacidade de adquirir fatores produtivos mais baratos do que suas concorrentes, melhores conhecimentos e/ou controle sobre métodos produtivos mais eficientes, posse de melhores cadeias de distribuição e maiores expertises sobre diferenciação de produtos etc. Trata-se de preservar o monopólio de suas habilidades e funções em mercados externos, sendo assim cauteloso no uso de seus recursos.

A Teoria do Ciclo de Vida do Produto foi desenvolvida por Raymond Vernon (1966), considerando o padrão de consumo e a inovação nos EUA, ${ }^{4}$ e explica os fluxos de investimentos no exterior por meio da coordenação da firma sobre o ciclo de vida do produto e sobre a corrente internacional de investimentos. Vernon (1966) argumenta que os investimentos internacionais estão intimamente ligados ao desenvolvimento de novas tecnologias e ao emprego destas na fabricação de novos produtos, sendo que para tanto é necessário ter acesso à mão de obra qualificada e investir em P\&D, geralmente encontrados em países desenvolvidos.

À época da elaboração de sua teoria, o autor acreditava que os EUA reuniam as melhores condições para o desenvolvimento de novos produtos: renda per capita elevada, existência de demanda em função dos níveis salariais elevados e uma baixa taxa de poupança, menores custos de comunicação etc. Mas, à medida que novos fabricantes passassem a produzir o mesmo produto e a produção se tornasse cada vez mais padronizada, maior seria a necessidade de encontrar meios de reduzir os custos de produção, o que poderia ser alcançado 
pela internacionalização da produção. Dessa forma, o autor sugere que a inovação tecnológica passa por três estágios de maturação que definem o ciclo de vida do produto, o que influi na busca de vantagens competitivas por meio de fatores produtivos mais baratos. Esses estágios são: 1) produto novo (pouco padronizado e monopolizado, produzido por trabalho especializado e vendido a consumidores de alta renda); 2) produto maduro (produzido em ambiente com alguma concorrência, de forma parcialmente padronizada e com trabalho menos especializado e mais barato); e 3) produto padronizado (produzido de forma totalmente padronizada, em ambiente de elevada concorrência e mão de obra não especializada).

Peter Buckley e Mark Casson (1976), responsáveis pela Teoria da Internalização, consideram que uma empresa decidirá operar no exterior por meio de IDEs quando os custos líquidos associados à realização dessas inversões forem menores do que aqueles associados às transações via mercados imperfeitos, notadamente quando se considera as transações internacionais de insumos intermediários. Dado que os mercados são imperfeitos e essas imperfeições elevam os custos de transação, as próprias empresas realizam as atividades no exterior com a intenção de reduzir esses custos e maximizar os lucros. Isso permite que as empresas também controlem atividades de agregação de valor, ação em que reside parte considerável da geração de lucros.

De acordo com Mariotto (2007), Buckley e Casson enfatizaram, do mesmo modo, a comercialização dos produtos intermediários: produtos semiacabados, componentes, conhecimento e experiência. Nesse caso, expõe o autor (MARIOTTO, 2007, p. 61) que o problema é que, "em geral, os mercados para muitos desses produtos intermediários ou não existem ou são imperfeitos, particularmente através de fronteiras internacionais". Nesse aspecto, a Teoria da Internalização defende que as Empresas Transnacionais (ETNs) podem resolver esse problema na medida em que transacionam produtos inter- 
mediários entre unidades de uma mesma empresa que atuam em países diferentes.

A Teoria da Escola de Uppsala, criada, entre outros, por Jan Johanson e Jan-Erik Vahlne, tem como seus dois principais pontos a internacionalização como resultante da obtenção gradual de conhecimento sobre o mercado em que se pretende atuar e a ideia de distância psíquica. A abordagem surge como resultado dos estudos realizados pela Universidade de Uppsala sobre a internacionalização de grandes empresas da Suécia, os quais constataram que esse processo era consequência do conhecimento gradual que a firma acumulava sobre o mercado em que ela queria investir e pelo aumento do comprometimento com o mesmo. A empresa começaria exportando e chegaria ao ponto de estabelecer filiais, como resultado do aumento do conhecimento que se tem daquele mercado. Outra ideia desenvolvida por essa linha de pensamento foi o conceito de distância psíquica, que consiste no conjunto de fatores diversos (políticos, sociais, econômicos, culturais etc.) que aproximam ou afastam o país investidor do receptor. Por exemplo, se um Estado tem identificação cultural com outro país, seria mais fácil investir nesse país ao invés de outro com cultura distinta (JOHANSON; VAHLNE, 1977; 2009; NEUMANN; HEMAIS, 2005; AMATUCCI, 2009; MARIOTTO, 2007).

Finalmente, para Dunning (1988a; 1988b; 2001), criador do Paradigma Eclético, a decisão de uma empresa em investir no exterior depende da disposição do que ele convencionou chamar de vantagens OLI (referentes às palavras inglesas Ownership, Location e Internalization). As vantagens de propriedade compreendem os ativos intangíveis específicos das empresas e a sua própria capacidade de coordená-los fora de suas fronteiras e de beneficiar-se deles entre os seus concorrentes, como já indicaram a Teoria do Poder de Mercado e a Teoria da Internalização. Entre essas vantagens, podem ser elencadas a posse de tecnologias avançadas, de processos produtivos e 
distributivos mais eficientes, de melhores capacidades de gestão etc. Elas são condições básicas para a própria existência das empresas que buscam operar no exterior por meio de IDEs, dado que são prerrogativas que dão à empresa um diferencial, um ativo que pode ser explorado além das fronteiras de seu país de origem e que de alguma forma compensa o fato de a empresa ser estrangeira.

O autor argumenta que as vantagens de localização se referem aos fatores específicos de cada economia e que por isso são imóveis, intransferíveis e não comercializáveis. Em outras palavras, são fatores que influenciam na localização das empresas e estão muito vinculados ao que o país receptor tem a oferecer, sendo que, para que deles se beneficiem, as empresas têm que estar presentes nesses locais. São assim classificadas como vantagens locacionais a estrutura do mercado, o câmbio, as condições de remessas de lucros e dividendos, a concorrência, o custo dos fatores produtivos (mão de obra, matéria-prima etc.), as barreiras tarifárias, entre outras.

A terceira e a última vantagem é a da internalização, que é resultante das falhas do mercado, ou melhor, da imperfeição deste, como a falta de informação e as incertezas das transações devido à falta de confiança e de controle sobre os agentes do mercado. Diante disso, as empresas que têm interesses em se internacionalizar devem mensurar os custos dos tipos de internacionalização, como licenciamento, exportação ou IDEs.

Os determinantes dos IDEs também são importantes na Teoria Eclética. Dunning (1988a) classificou os determinantes que motivam as empresas a se internacionalizarem em três: a busca de recursos, que reflete o interesse do investidor em ter o fornecimento orientado de determinados recursos, como os naturais; a busca de mercado, que está ligada à procura de dotações imóveis localizadas fora das fronteiras do país de origem (tamanho do mercado, renda per capita, acesso a mercados regionais e globais, estrutura do mercado etc.); e a 
busca de eficiência, que almeja o investimento racionalizado (reduzir custos relativos à produtividade da mão de obra, transportes e comunicações; aproveitar as vantagens de um acordo de integração regional etc.). Poder-se-ia acrescentar também a busca por ativos estratégicos com um quarto determinante. Cabe notar, contudo, que esses determinantes, segundo a UNCTAD (1998), são considerados determinantes econômicos, não sendo por si só capazes se explicar todas as motivações das saídas dos IDEs, haja vista que a análise da estrutura política dos países de acolhimento, da mesma forma que o ambiente dos negócios, também é elemento central na hora de decidir onde investir, como se argumenta na próxima seção.

Posteriormente, Dunning (2001) passou a destacar que as empresas estão cada vez mais usando os IDEs como forma de aumentar e/ou adquirir mais vantagens competitivas ao invés de apenas explorar as suas vantagens de propriedade, o que passou a ser chamado de busca de ativos estratégicos. Elas estão participando mais da economia internacional, buscando acesso às novas tecnologias, habilidades e competências, estratégias de marketing e novos bens, da mesma forma que almejam aproveitar os benefícios de outros sistemas educacionais e de inovação, por exemplo.

As cinco teorias explicam o comportamento dos IDEs ou das ETNs da perspectiva da empresa. Porém, defende-se aqui o argumento de que elas não são suficientes, isoladas ou mesmo em conjunto, para fornecer elementos necessários ao entendimento de todo o processo de IDE. A hipótese deste trabalho é que, principalmente no caso da China, alguns investimentos aparentemente possuem objetivos geopolíticos. ${ }^{5}$ A insuficiência das teorias citadas resulta de dois aspectos. Primeiro, as teorias foram elaboradas com um forte viés ocidental. A Teoria do Poder de Mercado de Hymer foi influenciada pelo contexto histórico de sua época - a expansão das empresas norte-americanas pelo mundo, principalmente no Canadá e na Europa. Vernon também desenvolveu a sua interpretação a partir do contexto 
de inovação e do padrão de consumo norte-americano. Neumann e Hemais (2005, p. 35) sugerem explicitamente que a Teoria da Internalização "tenta explicar porque a firma se desenvolveu no sistema econômico ocidental". A Teoria Eclética foi resultado de análises da atuação de subsidiárias norte-americanas atuando na Inglaterra (DUNNING, 2001). Por sua vez, a Teoria da Escola de Uppsala foi desenvolvida a partir de estudos de casos do processo de internacionalização de empresas suecas do ramo farmacêutico e de engenharia. São visões, portanto, que refletem a realidade ocidental, a qual pode não representar de forma acurada a realidade chinesa, uma economia emergente marcada pela centralização de poder e que tem nas EPEs as suas principais ETNs. Conforme Zhang e Daly (2011, p. 392):

\begin{abstract}
A teoria tradicional [Teoria Eclética] sugere três motivações primárias para o IDE: busca de mercado estrangeiro, busca de eficiência e busca de recursos [...]. No entanto, a teoria tradicional sobre IDE é usada para explicar o investimento estrangeiro a partir da perspectiva de uma economia desenvolvida, no caso das economias emergentes como a China, precisamos de aplicações mais especializadas da teoria.
\end{abstract}

Em segundo lugar, na literatura já foram apontadas muitas falhas de cada teoria que por razões de espaço não cabe aqui reproduzir (TEECE, 2006; ANDREFF, 2000). As teorias têm um enfoque econômico (abordagens econômicas) ou comportamental (comportamento gradual). Dessa forma, são complementares, mas, mesmo em conjunto, incompletas. Isso porque elas enfatizam exclusivamente os ganhos e as perdas econômicas dos investimentos por meio dos IDEs, mas não os consideram como possíveis instrumentos geopolíticos de projeção internacional de um país. Neste caso, o cálculo econômico de ganhos e perdas poderia ser secundário, ou pelo menos tão importante quanto a ampliação da esfera de influência política, como parece ser o caso de alguns investimentos chineses discutidos abaixo. 


\section{Investimentos Diretos Externos Chineses: Evolução e Determinantes}

Esta seção discute algumas características da evolução recente, quantitativa e qualitativa, dos IDEs chineses, e postula a existência de determinantes extraeconômicos na consecução dos mesmos. A participação relativa dos países em desenvolvimento enquanto fontes de IDEs tem aumentado quando comparada à dos países desenvolvidos, sendo o caso da China ilustrativo (UNCTAD, 2012a). O país se transformou em 2011 na principal origem desse tipo de investimentos entre aquele grupo de países (Gráfico 1), e a tendência é que se torne o maior entre todos os países do mundo até o final de 2014 (Gráfico 2).

Rosen e Hanemann (2009) destacam o rápido crescimento dos IDEs chineses. De próximo de zero no início da abertura até 2004, experimentou uma grande elevação nos anos 2007 e 2008. A trajetória de internacionalização das empresas chinesas por meio de IDEs desde

\section{Gráfico 1}

Estoque de IDE de Países Selecionados entre 2001-2011 (Porcentagem do Total Mundial)

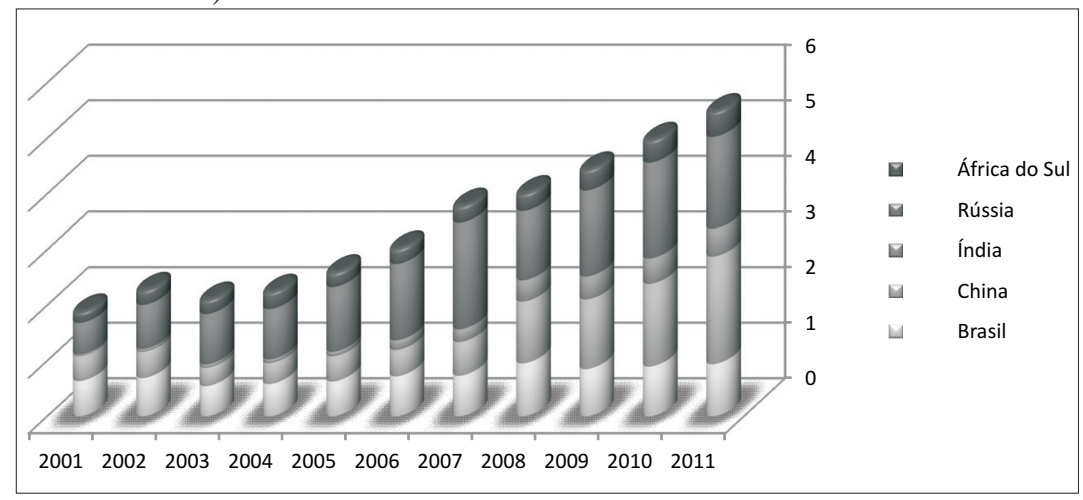

Fonte: UNCTAD (2012b). Elaboração dos autores. Seguindo a metodologia adotada pela UNCTAD, aos dados correspondentes à China não se incluem os de Hong Kong (China), Macao (China) e nem da Província de Taiwan. 


\section{Gráfico 2}

As mais Promissoras Economias de Origem de IDEs para 2012-2014

(Porcentagem das Agências de Promoção de Investimentos (IPA)

Entrevistadas sobre as Economias Selecionadas como as Principais Fontes de IDEs)

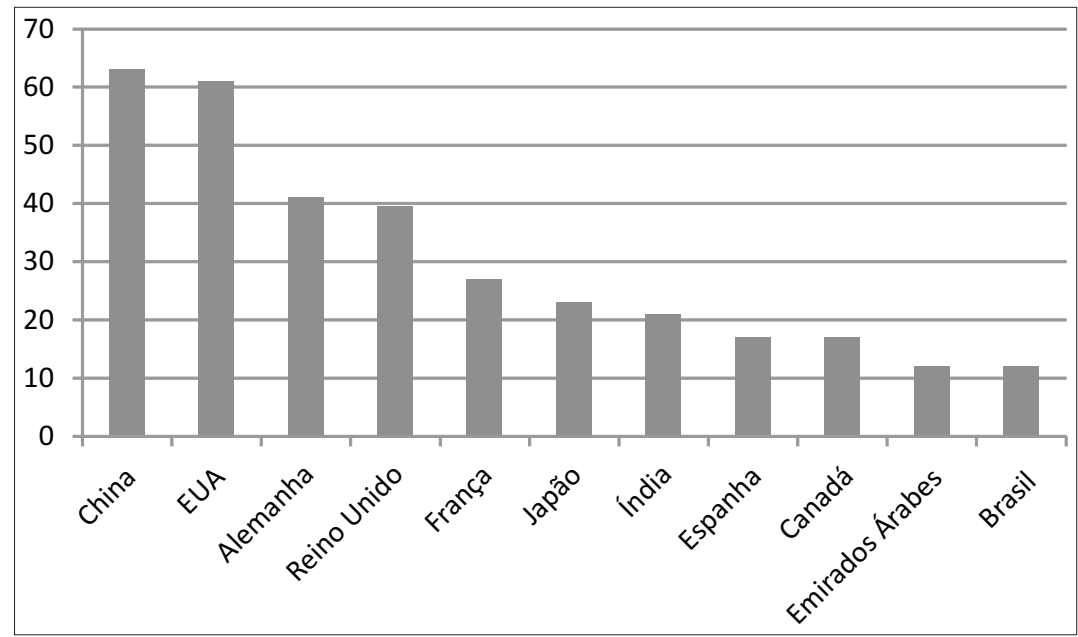

Fonte: UNCTAD survey, baseada em 62 respostas das IPAs (apud UNCTAD, 2012a, p. 21).

1978 pode ser divida em cinco fases, considerando-se o processo de avaliação e de aprovação realizado pelas autoridades do país sobre os projetos de investimento no exterior. Segundo Zhang (2005), as fases são: 1) "fase da aprovação caso a caso" (1979-1983); 2) fase da "padronização dos procedimentos de aprovação" (1984-1992); 3) fase do "aperto da gestão sobre o investimento no exterior" (1993-1998); 4) fase de incentivo aos "projetos de processamento comercial no exterior" (1999-2002); e 5) fase da "aplicação integral da Estratégia 'Atuação Global'”. Esta última consiste em uma política de incentivo realizada pelo Estado voltada para a expansão e para a intensificação do processo de internacionalização das empresas chinesas, embasada no uso das reservas cambiais do país, que compreende: 1) a racionalização dos procedimentos administrativos; 2) o afrouxamento do controle de câmbio; 3) a prestação de informações e orientações; e 4) a redução dos riscos aos investimentos. 
A estratégia supracitada explica grande parte do aumento recente dos IDEs chineses pelo mundo, investimentos que são realizados majoritariamente por ETNs chinesas de propriedade estatal, principalmente do governo central, o que indica o importante peso do Estado na realização e direcionamento dos IDEs de acordo com seus interesses nacionais. Segundo o Relatório Internacional de Investimentos de 2011 (UNCTAD, 2011), em 2010 foi identificado um total de 653 ETNs de propriedade estatal no mundo, sendo que cinquenta delas pertenciam ao governo chinês $(7,7 \%$ do total), o que garante à China o segundo lugar entre os países que possuem esse tipo de empresa ${ }^{6}$ (Gráfico 3).

Analisando-se a presença das cinco principais ETNs não financeiras chinesas por ativos e estoques de IDEs no exterior, dispostas na Tabela 1, tem-se que: a) todas são EPEs; b) quatro são as maiores tanto em ativos como em IDEs; e c) com exceção da China Unicom Corpo-

\section{Gráfico 3}

As Maiores Economias do Mundo e suas ETNs de Propriedade Estatal (2010)

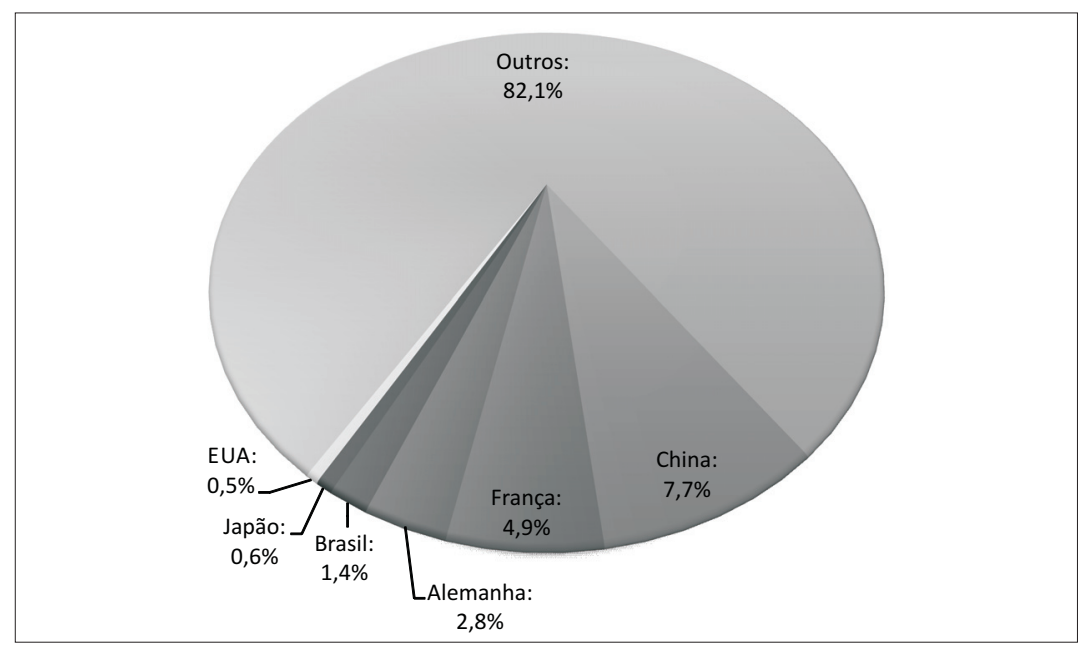

Fonte: UNCTAD (2011). Elaboração dos autores.

Nota: Não foram divulgados dados sobre o Reino Unido, atualmente a sexta maior economia do mundo. 
ration (comunicação) e da China Ocean Shipping (group) Company, todas as outras três estão ligadas aos recursos naturais/energia (MOFCOM, 2011).

\section{Tabela 1}

As 5 Maiores ETNs Chinesas não Financeiras Ranqueadas por Estoques de IDEs no Estrangeiro e também por Ativos (2010)

\begin{tabular}{c|l|l}
\hline NE & Estoques de IDEs & Ativos \\
\hline 1 & China Petrochemical Corporation & China Unicom Corporation \\
2 & China National Petroleum Corporation & China National Petroleum Corporation \\
3 & China National Offshore Oil Corporation & China Petrochemical Corporation \\
4 & China Resources (Holdings) Co., Ltd. & China Resources (Holdings) Co., Ltd. \\
5 & China Ocean Shipping (Group) Company & $\begin{array}{l}\text { China National Offshore Oil } \\
\text { Corporation }\end{array}$ \\
\hline
\end{tabular}

Fonte: MOFCOM (2011). Elaboração dos autores.

Considerando os estoques de IDEs no exterior por atividade, em 2010, as principais eram de serviços de locação e de negócios, bancos, mineração, vendas por atacado, manufatura e transporte. Um setor que chama a atenção é o de pesquisa científica, assistência técnica e prospecção geológica. Nele os estoques de IDEs chineses no exterior passaram de cerca de US\$ 124 milhões em 2004 para cerca de US\$ 4 bilhões em 2010 (MOFCOM, 2011).

Quando analisados os estoques dos IDEs chineses nos dez maiores países em reservas de petróleo, no período de 2004-2010, constata-se um aumento em todos os casos, como indica a Tabela 2, o que sugere uma intenção do governo chinês de criar uma base internacional de fornecimento de recursos naturais fundamentais à segurança energética do país.

Para Zhang e Daly (2011), outros fatores que impulsionam a saída dos IDEs da China são o tamanho de sua economia e de seu comércio exterior e o ritmo de crescimento de ambos, assim como o anseio de adquirir tecnologias avançadas, competências de gestão e segurança 
Leandro Teixeira dos Santos e Marcelo Milan

\section{Tabela 2}

Estoque de IDE Chinês nos 10 Maiores Países com Reservas Provadas de Petróleo (US\$ Milhões)

\begin{tabular}{r|l|r|r|r|r|r|r|r}
\hline NE & Anos/Países & \multicolumn{1}{c|}{$\mathbf{2 0 0 4}$} & $\mathbf{2 0 0 5}$ & \multicolumn{1}{c|}{$\mathbf{2 0 0 6}$} & \multicolumn{1}{c|}{$\mathbf{2 0 0 7}$} & \multicolumn{1}{c}{$\mathbf{2 0 0 8}$} & \multicolumn{1}{c}{$\mathbf{2 0 0 9}$} & \multicolumn{1}{c}{$\mathbf{2 0 1 0}$} \\
\hline 1 & Venezuela & 26,78 & 42,65 & 71,58 & 143,88 & 155,96 & 271,96 & 416,52 \\
2 & Arábia Saudita & 2,09 & 58,45 & 272,84 & 404,03 & 620,68 & 710,89 & 760,56 \\
3 & Canadá & 58,79 & 103,29 & 140,72 & $1.254,52$ & $1.268,43$ & $1.670,34$ & $2.602,60$ \\
4 & Irã & 46,68 & 56,08 & 110,59 & 122,35 & 94,27 & 217,80 & 715,16 \\
5 & Iraque & 434,87 & 434,87 & 436,18 & 22,45 & 20,79 & 22,79 & 483,45 \\
6 & Kuwait & 2,53 & 1,23 & 6,31 & 0,51 & 2,96 & 5,88 & 50,87 \\
7 & Emirados Árabes & 46,56 & 114,53 & 144,63 & 234,31 & 375,99 & 440,29 & 764,29 \\
8 & Rússia & 123,48 & 465,57 & 929,76 & $1.421,51$ & $1.838,28$ & $2.220,37$ & $2.787,56$ \\
9 & Líbia & 0,87 & 33,06 & 70,83 & 378,62 & 81,58 & 42,69 & 32,19 \\
10 & Nigéria & 75,61 & 94,11 & 630,32 & 35,60 & 795,91 & $1.025,96$ & $1.210,85$ \\
\hline
\end{tabular}

Fonte: MOFCOM (2011) e BP (2012). Elaboração dos autores.

Nota: Os dados para 2004-2006 incluem apenas os estoques não financeiros de IDE.

no fornecimento de recursos para garantir a produção doméstica. Adicionalmente, acrescentam que a China não hesitou em investir em países com sérios problemas institucionais, como no antigo Sudão. As motivações acima estão em consonância com a circular conjunta lançada em outubro de 2004 pela Comissão Nacional de Desenvolvimento e Reforma e pelo Banco de Exportação e Importação da China, a qual busca incentivar as inversões no exterior em áreas específicas, como:

(1) projetos de exploração de recursos para atenuar a escassez interna de recursos naturais; (2) projetos que promovam a exportação nacional de tecnologias, produtos, equipamentos e trabalho; (3) centros internacionais de P\&D [pesquisa e desenvolvimento] para utilizar tecnologias avançadas em nível internacional, habilidades gerenciais e profissionais; e (4) [fusões e aquisições] que poderiam aumentar a competitividade internacional das empresas chinesas e 
Segundo Davies (2010), a China nos últimos anos promoveu a diversificação dos seus investimentos, tanto entre os setores, como, por exemplo, o aumento da participação no setor de serviços, quanto entre as áreas geográficas. $\mathrm{O}$ autor também acredita que a crise financeira global vem se apresentando como uma oportunidade para o país aumentar a sua participação na economia mundial.

Contudo, para além dos aspectos econômicos, alguns autores argumentam que o atual cenário internacional está passando por uma fase de reordenamento das relações internacionais de poder (LAYNE, 2012). E a China aparentemente está se utilizando da situação para adquirir um status mais proeminente no mundo, por vários meios. Aqui se propõe a hipótese de que, entre esses meios, estão os IDEs, que podem não estar perseguindo apenas os objetivos econômicos que motivam a maioria dos investidores, como a maximização dos lucros. Este parece ser o caso em muitas situações nas quais os objetivos parecem ser mais geopolíticos do que econômicos. Isso não significa, da mesma forma, que o país está em busca apenas do controle sobre ativos politicamente estratégicos e que os determinantes econômicos devam ser minimizados. Mas por meio dos IDEs a China pode expandir sua influência pelo mundo e ocupar importantes posições no tabuleiro do jogo internacional de poder, questão que as teorias tradicionais dos IDEs não conseguem incorporar, dado o objeto que se propõem a explicar e o escopo das mesmas.

Cabe observar, contudo, que a presença de objetivos geopolíticos nos IDEs chineses é de difícil observação direta, pela sua própria natureza. Apenas na situação em que prejuízos sustentados por longos períodos em um determinado país ou região não alterassem planos de expansão dos investimentos nos mesmos seria possível inferir outras motivações para os IDEs. E ainda assim os determinantes geopolíticos poderiam não ser necessariamente os determinantes mais impor- 
tantes. Por outro lado, a existência de retornos positivos não é incompatível com orientações geopolíticas dos IDEs. Desta forma, os aspectos destacados a seguir são apenas indicações de um fenômeno complexo que exige mais pesquisas e estudos que permitam testar a hipótese dos determinantes geopolíticos dos IDEs chineses de forma mais robusta. A seguir são apresentados indicadores indiretos, resultado de observações ainda não sistematizadas sobre o fenômeno.

O ingresso da China na África sugere um exemplo de como os IDEs podem não obedecer apenas às finalidades econômicas. Além de recursos naturais e da exploração de novos mercados que estão surgindo, a China parece buscar a construção de aliados a partir de seus interesses geopolíticos. O continente é composto por 54 países que têm voto na Assembleia Geral da Organização das Nações Unidas e que, alguns deles, foram importantes na ascensão da China continental ao Conselho de Segurança em detrimento de Taiwan. ${ }^{7}$ São atores que anseiam por ajuda em seu processo de desenvolvimento, têm ligações históricas e compartilham dos princípios defendidos por Pequim, apresentando assim menor resistência à presença chinesa. Da mesma forma, a África não é uma das prioridades da superpotência norte-americana, o que facilita a projeção chinesa sobre o continente. Se a África oferece retornos elevados para os IDEs, seria preciso explicar, considerando apenas os determinantes econômicos, o reduzido volume, em termos relativos, de IDEs norte-americanos na região. Se não oferece, é preciso então explicar a rápida expansão dos IDEs chineses no continente. Em ambos os casos, as motivações geopolíticas poderiam explicar este padrão de IDE, com os EUA não tendo interesse geopolítico na região, ou preferindo lançar mão de outros meios, e a China sendo motivada por aspectos econômicos, mas também geopolíticos.

Da mesma forma, a presença da China na região latino-americana pode fazer parte de seu interesse de cunho neorrealista de projeção internacional "segundo o qual Pequim usa o comércio, o investimen- 
to, as ajudas ao desenvolvimento e a diplomacia com a intenção de equilibrar a dominância regional e global dos Estados Unidos e outras nações da OCDE" (DOSCH; GOODMAN, 2012, p. 3-4), aproveitando-se de um vácuo de poder deixado pelos norte-americanos e pelos russos. As inversões chinesas na região têm preocupado o governo norte-americano sobre o risco potencial de seu uso futuro no suporte ao Exército de Libertação Popular (ELP) em um contexto de conflito sino-norte-americano (ELLIS, 2011). Por exemplo, os investimentos chineses em atividades de aviação, espacial, telecomunicações e portuárias podem aumentar as capacidades militares do ELP. Segundo Ellis (2011, p. 38),

Como em aviação e espacial, atividades chinesas em telecomunicações têm implicações estratégicas militares em duas áreas. Primeiro, elas dão suporte a esforços chineses para adquirir e aperfeiçoar capacidades tecnológicas nesse setor estrategicamente importante. Segundo, como um complemento à cooperação espacial, quando empresas chinesas vendem hardwares e constroem infraestruturas de telecomunicações na região, a RPC é beneficiada com oportunidades para explorar estas redes para coleta de informação futura e atividades de ruptura em um improvável, porém possível, evento de conflito futuro com os Estados Unidos.

O Brasil é o terceiro principal destinos dos IDEs chineses no mundo, dos quais cerca de $78 \%$ do total são realizados por EPEs (CEBC, 2013). Os $22 \%$ restantes são realizados por empresas propriamente privadas e outras sobre as quais incidem dúvidas referentes à real natureza de sua propriedade, como a ZTE e a Huawei. Nesse sentido, Peters (2012) destaca que os IDEs chineses são qualitativamente diferentes dos IDEs de outras nacionalidades encontrados na região latino-americana, em função de sua estrutura de propriedade e por seu 
processo de aprovação não ser neutro (ligação com o Estado). Logo, sugere atenção às relações políticas e estratégicas a eles subjacentes.

A situação é bem diferente do que acontece com os investimentos em alguns países desenvolvidos, como EUA, Austrália e Alemanha, nos quais a China registra as maiores perdas. ${ }^{8}$ Dado que são alguns dos principais destinos das empresas chinesas, seria de se esperar que, quanto maior a quantidade de investimentos, maiores as possibilidades de prejuízos. Todavia, esses Estados são lideranças mundiais e não permitirão tão facilmente a entrada da China, tanto internamente quanto em sua área de influência, o que obviamente não faz sentido de uma perspectiva puramente econômica, ainda que os efeitos econômicos dos IDEs sejam objetos de controvérsias (CONTESSI; WEINBERGER, 2009). Neste sentido, alguns casos de bloqueios aos investimentos chineses no Canadá, nos Estados Unidos e na Austrália chamaram a atenção pelo fato de todos envolverem supostas ameaças à segurança nacional. Esses países parecem temer que os IDEs chineses possam efetivar intenções políticas de Pequim, isto é, interesses geopolíticos maquiados pelas EPEs, que funcionariam como um meio pelo qual eles tentam ser alcançados. Este aspecto dos IDEs, caso a hipótese deste trabalho não possa ser rejeitada, pode ser entendido como uma forma de busca de poder nacional.

Especificamente com relação ao Canadá, os IDEs chineses se concentram na exploração de recursos naturais. As inversões podem ser usadas para dinamizar o setor, mas o governo canadense faz ressalvas aos mesmos alegando a salvaguarda da segurança nacional. Szamosszegi e Kyle (2011) afirmam que as dúvidas recaem sobre a falta de clareza das reais intenções dos IDEs chineses, sobre o fato de o controle corporativo das empresas estar nas mãos do Estado e do Partido Comunista Chinês (PCC), sobre a existência de células do PCC dentro das principais empresas exercendo influência nas decisões de negócios e sobre a natureza de seu sistema político - não democrático e comunista. Segundo Smart (2012, p. i), "a estratégia por trás dos 
investimentos externos da China em países como o Canadá é especificamente dirigida à promoção dos próprios objetivos de segurança nacional e de influência geopolítica”.

Sobre os IDEs chineses bloqueados nos Estados Unidos, dois eventos sugerem motivações geopolíticas: um na área de recursos naturais, com a tentativa de aquisição da União da Companhia de Petróleo da Califórnia (UNOCAL), e outro na área de tecnologia, a tentativa de entrada da Huawei no mercado norte-americano. A frustação da negociação da Corporação Nacional Chinesa de Petróleo Ultramarina (CNOOC, na sigla em inglês) na aquisição da UNOCAL em 2005 exemplifica bem como os investimentos chineses nos Estados Unidos podem ser interpretados sob um prisma geopolítico. De acordo com Barboza (2005), a EPE do ramo petrolífero almejava adquirir a companhia norte-americana de petróleo e gás por US\$18,5 bilhões. A CNOOC estava disposta a pagar valor superior a US\$ 20 bilhões para conseguir eliminar qualquer chance de a Chevron, uma das maiores empresas norte-americanas de petróleo, conseguir comprar a empresa. O impasse acabou por se refletir inclusive em tensões comerciais e políticas entre os dois países. A CNOOC não conseguiu finalizar a compra e externou que, mesmo que conseguisse, enfrentaria fortes riscos políticos, levando especialistas chineses a externar que o risco político apresentado ao investimento foi maior nos EUA do que na África e no Oriente Médio. Os norte-americanos alegaram que o interesse da CNOOC pela UNOCAL representava uma ameaça, no longo prazo, aos interesses energéticos do país. ${ }^{9}$

O caso da tentativa de entrada da Huawei no mercado norte-americano não foi diferente. O Comitê de Investimentos Estrangeiros dos Estados Unidos (CIEEU) não permitiu que ela comprasse, entre outras, a 3Leaf Systems, do ramo de TI, em 2007, e que vendesse equipamentos de TI para a Sprint Nextel, em 2010, companhia que abastece os militares norte-americanos e o setor privado com hardwares e softwares. No caso da Nextel, o Congresso norte-americano acusou a 
Huawei de ciberespionagem em nome de Pequim, de desrespeito à propriedade intelectual, de possível fornecimento de tecnologia ao Regime de Saddam Hussein e ao Talibã, além de ligações com a indústria militar iraniana, com a Guarda Revolucionária Islâmica e com o EPL da China, neste último caso pelo fato de o fundador da empresa, Ren Zhenfei, ter servido no EPL como técnico em telecomunicações. A denúncia contendo essas informações foi feita pelo Senado norte-americano à alta cúpula do governo (UNITED STATES SENATE, 2010).

A acusação envolveu a inteligência norte-americana e expôs a preocupação de que os hardwares e softwares providos pela Huawei poderiam conter "portas traseiras" ou tecnologias suspeitas que facilitariam a atuação de hackers militares chineses. O Senado também perguntava se havia comunicação entre a Agência de Defesa Nacional, a Agência Central de Inteligência e a Agência Nacional de Segurança, entre si e com agências estrangeiras de inteligência que investigavam a atuação da Huawei. $\mathrm{O}$ fato de a China já poder desenvolver uma guerra cibernética e dos possíveis laços da Huawei com o EPL já tinha provocado investigações da inteligência dos países com os quais a empresa mantinha transações (UNITED STATES SENATE, 2010).

No caso australiano, o governo tem aumentado o escrutínio sobre os IDEs chineses com a intenção de "combater o risco potencial de comportamento não comercial e/ou o risco de transações não isentas de interesses entre as partes" (LARUM; QIAN, 2012, p. 10), os quais podem representar uma ameaça à segurança nacional. Trata-se de uma avaliação mais apurada em que os IDEs chineses, principalmente aqueles ligados direta ou indiretamente ao governo, estão sendo submetidos, resultando entre os investidores chineses no aumento do sentimento de falta de confiança e da sensação de que as suas inversões estão sendo discriminadas. Argumentou-se que era uma decisão prudente com relação à preservação da segurança doméstica australi- 
ana, em razão da ameaça que a Huawei apresentava a esta em função de supostos atos de ciberespionagem por parte dos militares e do governo chinês por meio da empresa, considerada pouco transparente.

\section{Alargamento Teórico da Teoria Eclética: A Busca de Poder Nacional}

Esta seção procura qualificar as teorias da internacionalização das empresas, em particular a Teoria Eclética, a partir da hipótese de que os IDEs podem ser entendidos também como possíveis instrumentos de influência geopolítica. Esta teoria foi escolhida em função de sua abrangência, uma vez que reúne várias das demais teorias sobre a internacionalização de empresas. Assim, a Teoria Eclética também defende alguns elementos da Teoria da Escola de Uppsala, como a distância psíquica, e a evolução mais recente desta, que passou a considerar a influência das networks ou das redes de relacionamentos no processo de internacionalização (JOHANSON; VAHLNE, 2009), questão que é discutida por Dunning (1997) em seu livro Alliance Capitalism and Global Business. Os casos dos IDEs chineses na África, bem como os vetos políticos aos mesmos na Austrália, no Canadá e nos Estados Unidos, assim como os estreitos vínculos das EPEs com o Estado e com o PCC, parecem indicar que essas inversões podem estar cumprindo objetivos geopolíticos do governo chinês. Dessa forma, uma das maneiras de inserir, na Teoria Eclética, o possível uso geopolítico dos IDEs chineses, e possivelmente dos IDEs de outras nacionalidades, é por meio da inclusão de objetivos não exclusivamente econômicos, como a busca de poder nacional.

Para acomodar os elementos geopolíticos, a Teoria Eclética teria de incorporar a busca de poder nacional entre os determinantes dos IDEs. As vantagens OLI indicadas por Dunning estão muito ligadas à percepção das empresas, sobretudo de propriedade privada, ao nível do investidor que busca maximizar os lucros de seus investimen- 
tos. Por consequência, há a necessidade de entender alguns IDEs a partir também da lógica das EPEs, ou seja, compreendê-los em nível de país dotado de interesses nacionais que estão em uma esfera diferente de importância quando comparados aos interesses estritamente econômicos. A busca de poder nacional compreende a conveniência da realização de investimentos, sendo o Estado o investidor, a partir do interesse nacional que pode ser refletido em objetivos geopolíticos, compostos por propósitos militares, políticos e culturais, pelo exercício de poder por meio da indução de comportamentos ou mesmo por propósitos econômicos. Entretanto, difere do interesse econômico dos investidores privados pelo fato de refletir o interesse de um Estado nacional.

Da mesma forma, esse determinante dos IDEs indica que o investidor, nesse caso o Estado, é motivado a investir no exterior por meio de suas EPEs na tentativa de elevar o seu poder e a sua influência nas relações internacionais, como no caso da China. Com este alargamento, é possível preencher uma importante lacuna existente nas teorias da internacionalização de empresas, as quais não consideram que os IDEs possam obedecer a objetivos geopolíticos, dando assim pouco destaque aos determinantes não econômicos, principalmente ao nível do Estado. As observações apresentadas, ainda que em números reduzidos, dizem respeito apenas ao caso chinês. Mas isso não deveria impedir avanços nessa questão. Da mesma forma que a Teoria da Escola de Uppsala foi generalizada a partir da experiência de umas poucas empresas de um único país, o caso chinês pode abrir novas fronteiras de pesquisa, repensando inclusive as experiências dos próprios países ocidentais e os padrões de IDEs norte-americanos durante a Guerra Fria.

\section{Considerações Finais}

As teorias da internacionalização apresentadas neste artigo sugerem que elas não conseguem explicar por completo as saídas de IDEs chi- 
neses. São teorias que, tomadas em conjunto, permitem entender os IDEs de forma mais ampla. Contudo, tanto em função de suas próprias limitações teóricas, quanto pela realidade da época e local onde foram criadas, não permitem entender que esse tipo de investimento também pode obedecer a interesses geopolíticos. Parte das preocupações manifestadas por alguns Estados pode resultar do desconhecimento que se tem sobre a China, dados o aumento exponencial de seus investimentos pelo mundo, como apresentado acima, e as implicações de negociar com uma economia singular. Mas podem não ser completamente infundados os temores de que Pequim estaria usando as ETNs de propriedade estatal como forma de alcançar também objetivos geopolíticos, expandindo sua influência na ordem internacional e avançando seus interesses nacionais. Seriam, portanto, peças-chave na reconfiguração do tabuleiro da ordem internacional. Mas esta hipótese é de difícil comprovação, já que Pequim dificilmente admitiria explicitamente a existência desses objetivos geopolíticos, sendo preciso aprofundar as pesquisas sobre essa questão.

Se, do ponto de vista empírico, as informações existentes não permitem aceitar ou rejeitar a hipótese, as poucas evidências até aqui coletadas sugerem elementos que apontam nesta direção, e do ponto de vista teórico avanços são necessários. O trabalho sugere que a Teoria Eclética incorpore a busca de poder nacional como uma forma de compreender melhor os determinantes dos fluxos e da localização dos IDEs chineses e de outros países, bem como outras questões não econômicas subjacentes. Esta possível ampliação da Teoria Eclética pode dotar os formuladores de políticas, pesquisadores e investidores de mais uma ferramenta que lhes auxiliem em suas interpretações e decisões sobre a dinâmica mundial dos IDEs. Do mesmo modo, sendo mais claramente compreendidos os possíveis interesses geopolíticos desses investimentos, podem os Estados receptores se protegerem melhor ou mesmo buscarem mecanismos de compatibilização de interesses, sem, é claro, ameaçar seus interesses nacionais, entre eles a segurança do país. 


\section{Notas}

1. Por exemplo, a celebração da parceria entre a TCL (equipamentos elétricos e eletrônicos) e a francesa Alcatel, em 2004, com o objetivo de acessar tecnologia de telefonia móvel, e a compra da empresa norte-americana IBM PC pela Lenovo (computadores), em 2005 (DONGHONG, 2009; LARÇON; BARRÉ, 2009).

2. Segundo Szamosszegi e Kyle (2011), as EPEs são importantes no direcionamento e no controle da economia chinesa. Trata-se da materialização da centralização do poder estatal e de um forte instrumento pelo qual o Estado norteia, regula, comanda e estimula a economia.

3. Mariotto (2007, p. 58) conceitua internalização da seguinte forma: "denomina-se 'internalização', ou 'integração', a decisão de uma firma de realizar atividades da sua cadeia de produção dentro da empresa, em vez de contar com outras empresas para realizar essas atividades e comprar delas seus insumos ou vender a elas seus produtos. É o contrário da terceirização. A empresa internaliza atividades quando percebe que, se contasse com outras empresas do mercado para realizar essas atividades, o custo seria maior."

4. Vernon não retratava todo tipo de inovação, por isso, destacou: "Neste ponto de exposição, é importante uma vez mais enfatizar que a discussão [...] se refere apenas à inovação de certos tipos de produtos, ou seja, aqueles associados com alta renda e aqueles que substituem o trabalho pelo capital. Nossa hipótese não diz nada sobre a inovação industrial em geral; este é um assunto maior do que temos abordado aqui" (VERNON, 1966, p. 193).

5. A primeira definição de geopolítica foi elaborada em 1899 por Rudolph Kjellen (apud COHEN, 2003, p. 11) como "teoria do Estado como um organismo geográfico ou fenômeno no espaço". Desde então, o conceito tem recebido a contribuição de inúmeros pensadores e por isso atualmente possui múltiplos significados (MAMADOUH, 1998; ATKINSON; DODDS, 2010; FLINT, 2006). Emprega-se aqui o seguinte entendimento: a interação entre o poder nacional e os interesses nacionais de determinado Estado na modificação ou estruturação da ordem internacional ao seu favor. Desta forma, a China pode estar usando as ETNs de propriedade estatal como forma de alcançar objetivos geopolíticos. Assim, os IDEs seriam um meio pelo qual o país se expande e influencia a ordem internacional de acordo com seus interesses nacionais.

6. O primeiro lugar é ocupado pela África do Sul, que possui 54 ETNs de propriedade estatal. 
Determinantes dos Investimentos Diretos

Externos Chineses: Aspectos Econômicos...

7. Parte dos investimentos chineses na América Latina e no Caribe também parece ser justificada pela intenção do governo chinês de isolar diplomaticamente Taiwan. Dos 23 países que atualmente mantêm relações diplomáticas com a ilha, onze estão localizados na América Latina e no Caribe (DOSCH; GOODMAN, 2012).

8. Os cinco países em que a China tem as maiores perdas são, respectivamente, Austrália, EUA, Irã, Alemanha e Nigéria (SCISSORS, 2011).

9. Nas palavras de Barboza (2005), "políticos em Washington saíram em forte oposição aos esforços da CNOOC para adquirir a UNOCAL, dizendo que a empresa estatal de petróleo estava agindo como um proxy para o governo chinês e procurava assegurar ativos de energia estrategicamente valiosos para os Estados Unidos".

\section{Referências Bibliográficas}

AMATUCCI, M. Teorias de negócios internacionais e a economia brasileira de 1850 a 2007. In: (Org.). Internacionalização de empresas brasileiras: teorias, problemas e casos. São Paulo: Atlas, 2009. cap. 1, p. 5-58.

ANDREFF, W. Multinacionais globais. Bauru: EDUSC, 2000.

ATKINSON, D.; DODDS, K. (Ed.). Geopolitical Traditions: A Century of Geopolitical Thought. Londres: Routledge, 2010.

BARBOZA, D. China Backs Away from Unocal Bid. The New York Times Business, ago. 2005. Disponível em: <http://www.nytimes.com/2005/ 08/02/business/worldbusiness/02iht-unocal.html>. Acesso em: 25 ago. 2012.

BP - British Petroleum. BP Statistical Review of World Energy. Jun. 2012. Disponível em: <http://www.bp.com/sectionbodycopy.do?category $\mathrm{Id}=7500 \&$ contentId=7068481>. Acesso em: 19 abr. 2013.

BUCKLEY, P.; CASSON, M. The Future of the Multinational Enterprise. Londres: Macmillan, 1976. 
Leandro Teixeira dos Santos e Marcelo Milan

CANTWELL, J. Technological Innovations in Multinational Corporations. Oxford: Blackwell, 1989.

CAVES, R. International Corporations: The Industrial Economics of Foreign Investment. Economica, v. 38, n. 149, p. 1-27, 1971.

COHEN, S. B. Geopolitics of the World System. Nova York: Rowman and Littlefield, 2003.

CEBC - Conselho Empresarial Brasil-China. Uma análise dos investimentos chineses no Brasil: 2007-2012. Rio de Janeiro: CEBC, jun. 2013.

CONTESSI, S.; WEINBERGER, A. Foreign Direct Investment, Productivity, and Country Growth: An Overview. Federal Reserve Bank of St. Louis Review, v. 91, n. 2, p. 61-78, Mar./Apr. 2009.

DAVIES, K. Outward FDI from China and its Policy Context. Columbia FDI Profiles: Country Profiles of Inward and Outward Foreign Direct Investment Issued by the Vale Columbia Center on Sustainable International Investment, out. 2010. p. 1-16. Disponível em: <http://www.vcc.columbia.edu/content/outward-fdi-china-and-its-policy-context-ken-davies>. Acesso em: 28 mai. 2013.

DONGHONG, L. Innovation \& Knowledge Transfer in Chinese Multinationals. In: LARÇON, J.-P. (Ed.). Chinese Multinationals. Singapore: World Scientific, 2009. Cap.7, p. 151-166.

DOSCH, J.; GOODMAN, D. China and Latin America: Complementarity, Competition, and Globalisation. Journal of Current Chinese Affairs, v. 41, n. 1, p. 3-19, 2012.

DUNNING, J. H. Alliance Capitalism and Global Business. Londres: Routledge, 1997.

. The Eclectic Paradigm of International Production: A Restatement and some Possible Extensions. Journal of International Business Studies, v. 19, n. 1, p. 1-31, jun. 1988a.

. Explaining International Production. Londres: Unwin Hyman, 1988b.

. The Eclectic (OLI) Paradigm of International Production: Past, Present and Future. International Journal of the Economics of Business, v. 8, n. 2, p. 173-190, 2001. 
ELLIS, R. E. China-Latin America Military Engagement: Good Will, Good Business, and Strategic Position. Carlisle: Strategic Studies Institute, U.S. Army War College, 2011.

FLINT, C. Introduction to Geopolitics. Londres: Routledge, 2006.

HYMER, S. H. The International Operations of National Firms: A Study of Direct Foreign Investment, 1960. Tese (Doutorado em Economia) - MIT Library, Cambridge, 1960.

JOHANSON, J.; VAHLNE. J.-E. The Internationalization Process of the Firm - A Model of Knowledge Development and Increasing Foreign Market Commitments. Journal of International Business Studies, v. 8, n. 1, p. 23-32, Mar. 1977.

. The Uppsala Internationalization Process Model Revisited: From Liability of Foreignness to Liability of Outsidership. Journal of International Business Studies, n. 40, p. 1.411-1.431, mai. 2009.

KINDLEBERGER, C. American Business Abroad. The International Executive, v. 11, p.11-12, 1969.

KOGUT, B.; ZANDER; U. Knowledge of the Firm and the Evolutionary Theory of the Multinational Corporation. Journal of International Business Studies, v. 34, n. 6, p. 516-529, 2003.

LARÇON, J.-P.; BARRÉ, G. Technology-based Competition and Chinese Multinationals. In: LARÇON, J.-P. (Ed.). Chinese Multinationals. Cingapura: World Scientific, 2009. Cap. 6, p. 127-149.

LARUM, J.; QIAN, J. A Long March: The Australia-China Investment Relationship. Sydney: Australia China Business Council, 2012.

LAYNE, C. This Time It's Real: The End of Unipolarity and the Pax Americana. International Studies Quarterly, v. 56, p. 203-213, 2012.

MAMADOUH, V. Geopolitics in the Nineties: One Flag, Many Meanings. GeoJournal, v. 46, n. 4, p. 237-253, dez. 1998.

MARIOTTO, F. L. Estratégia internacional da empresa. São Paulo: Thomson Learning, 2007.

MOFCOM - Ministry of Commerce People's Republic of Chin. 2010 Statistical Bulletin of China's Outward Foreign Direct Investment, Beijing, set. 
2011. Disponível em: <http://english.mofcom.gov.cn/aarticle/statistic/foreigninvestment/201109/20110907742320.html>. Acesso em: 18 abr. 2012.

NEUMANN, R. W.; HEMAIS, C. A. Produção internacional e comportamento organizacional no processo de internacionalização: podem as teorias explicar o comércio internacional? In: HEMAIS, C. A. (Org.). O desafio dos mercados externos. v. 2: Teoria e prática na internacionalização da firma. Rio de Janeiro: Mauad, 2005.

PETERS, Enrique Dussel. Chinese FDI in Latin America: Does Ownership Matter? Working Group on Development and Environment in the Americas, Washington, Discussion Paper n. 33, p. 1-23, Nov. 2012.

PITELIS, C. N.; SUGDEN, R. Nature of the Transnational Firm. Londres: Routledge, 2000.

ROSEN, D. H.; HANEMANN, T. Policy Brief: China's Changing Outbound Foreign Direct Investment Profile: Drivers and Policy Implications. Peterson Institute for International Economics, n. PB 09-14, p. 1-21, 2009.

SALIDJANOVA, N. Going Out: An Overview of China's Outward Foreign Direct Investment. USCC Staff Research Report, 2011. Disponível em: <http://www.dmssearch.gpo.gov/TextSearch.aspx ?ct=48\&q1= USCC+Staff+Research+Report\&image. $x=0 \&$ image. $y=0>$. Acesso em: 28 mai. 2013.

SCISSORS, D. Chinese Outward Investment: More Opportunity Than Danger. 2011. Disponível em: <http://www.heritage.org/research/reports/2011/07/chinese-outward-investment-more-opportunity-than-danger $>$. Acesso em: 28 mai. 2013.

SMART, J. Dancing with the Dragon: Canadian Investment in China and Chinese Investment in Canada. The School of Public Policy/SPP, Research Papers, v. 5, n. 27, p. 1-20, set. 2012. Disponível em: <http://policyschool.ucalgary.ca/sites/default/files/research/smart-dancing-dragon-final.pdf $>$. Acesso em: 23 mai. 2013.

SZAMOSSZEGI, A.; KYLE, C. An Analysis of State-owned Enterprises and State Capitalism in China. U.S.- China Economic and Security Review Commission, Washington, DC, p. 1-116, out. 2011. Disponível em: <http://origin.www.uscc.gov/sites/default/files/Research/10_26_11_CapitalTradeSOEStudy.pdf $>$. Acesso em: 18 abr. 2013. 
Determinantes dos Investimentos Diretos

Externos Chineses: Aspectos Econômicos...

TEECE, D. J. Re?ections on the Hymer Thesis and the Multinational Enterprise. International Business Review, v. 15, p. 124-139, abr. 2006.

UNCTAD - United Nations Conference on Trade and Development. World Investment Report 1998: Trends and Determinants. Nova York: United Nations, 1998.

World Investment Report 2011: Non-Equity Modes of International Production and Development. Nova York: United Nations, 2011.

. World Investment Report 2012: Towards a New Generation of Investment Policies. Nova York: United Nations, 2012a.

UNCTADStat: Devoted to Development. 2012b. Disponível em: $<$ http://unctadstat.unctad.org/ReportFolders/reportFolders.aspx >. Acesso em: 25 set. 2012.

UNITED STATES SENATE. We Write to... Washington, DC. 18 ago. 2010. Disponível em: <http://graphics8.nytimes.com/packages/pdf/business/ 20100823-telecom.pdf>. Acesso em: 25 set. 2012.

VERNON, R. International Investment and International Trade in the Product Cycle. Quarterly Journal of Economics, v. 80, n. 2, p. 190-207, mai. 1966.

ZHANG, K. Canada in China: Going Global: The Why, When, Where and How of Chinese Companies' Outward Investment Intentions. Asia Pacific Foundation of Canada, n. 5, p. 3-44, nov. 2005.

ZHANG, X.; DALY, K. The Determinants of China's Outward Foreign Direct Investment. Emerging Markets Review, v. 12, n. 4, p. 389-398, dez. 2011.

\section{Resumo}

\section{Determinantes dos Investimentos Diretos Externos Chineses: Aspectos Econômicos e Geopolíticos}

A China tornou-se em 1993 o principal receptor de Investimentos Diretos Externos (IDEs) entre os países em desenvolvimento, e até 2014 será a prin- 
cipal origem desses investimentos no mundo de acordo com a UNCTAD (2012a). O objetivo deste artigo é estudá-la enquanto origem de fluxos de IDEs com possíveis determinantes geopolíticos. A partir de uma revisão da literatura, sugere-se que as principais teorias da internacionalização de empresas não conseguem explicar completamente os IDEs quando estes podem estar sendo influenciados por aspectos geopolíticos. Argumenta-se, então, que a Teoria Eclética da internacionalização pode preencher esta lacuna, caso incorpore como determinantes dos IDEs objetivos nacionais como a busca de poder nacional. Este elemento adicional possibilitaria caracterizar os IDEs chineses como instrumentos para a consecução de objetivos geopolíticos.

Palavras-chave: China - IDEs - Internacionalização - Geopolítica

\section{Abstract}

\section{Determinants of Chinese Foreign Direct Investment: Economic and Geopolitical Aspects}

China has become since 1993 the largest recipient of Foreign Direct Investments (FDI) among developing countries, and by 2014 it will be the main source of these investments in the world according to UNCTAD (2012a). The objective of this work is to study China as a source of FDI flows possibly presenting geopolitical determinants. It suggests, using a theoretical survey, that the main theories of internationalization of firms cannot fully explain FDIs when they may be influenced by geopolitical objectives. It therefore argues that the Eclectic Theory of Internationalization can fill this gap, to the extent that it adds national goals, such as national power seeking, in its framework. This additional element could allow further characterizing the Chinese FDIs as tools to advance geopolitical objectives.

Keywords: China - FDI - Internationalization - Geopolitics 